\title{
Microbial biopolymers in biomedical field
}

\begin{abstract}
Biodegradable plastics has gained significant commercial interest in recent years as they are having similar properties to that of the synthetic plastic used now a days, they are completely bio-degradable, are produced from natural (microbial) sources and are biocompatible in human system. These properties make PHB as an ideal candidate for various applications in medical field. The present article focuses on new developments in application of Poly- $\beta$-hydroxybutyrate (PHB) as biodegradable polymer in biomedical field. Derivatives of PHB particularly 4 HB (4-hydroxy butyrate) units has been found useful in the treatment of narcolepsy.
\end{abstract}

Keywords: biodegradable polymer, bio-plastic, poly- $\beta$-hydroxy butyrate, phb

\author{
Volume 3 Issue 3 - 2016
}

\author{
Wani SJ, Shaikh SS, Sayyed RZ \\ 'Department of Biotechnology, Federal University of Technology, \\ Nigeria \\ ${ }^{2}$ Department of Microbiology, Imo State University of Owerri, \\ Nigeria
}

Correspondence: Riyaz Sayyed Z, Department of Microbiology, PSGVP Mandal's Arts, Science and Commerce

College, Shahada Dist, India, Email sayyedrz@gmail.com

Received: February 22, 2016 | Published: April 25, 2016

\section{Introduction}

Applications of non-biodegradable polymers in biomedical field pose many problems including their surgical removal after recovery/ surgery. In this regards bio-plastics of microbial origin have been seen as a potential material in the field of biomedical field as they are safer, completely biodegradable after their use and do not pose the problem of their surgical removal. Among the various types of biopolymers produced by microorganisms, a great demand is building up for Poly$\beta$-hydroxy butyrate (PHB) because of its suitable material properties like completely biodegradability, ${ }^{1}$ its biocompatibility, it supports cell growth, guide and organize cells which allow tissue in growth. These properties make PHB as an ideal candidate in various items preparation in medicine, surgery, pharmacology, transplantology and in tissue engineering scaffolds. In tissue engineering scaffold it is used as biopolymer porous substrates.

Biocompatibility and non-toxicity are the basic requirements for any material to be used in human system. Detailed research and analysis on biodegradation, biocompatibility and cytotoxicity assays in vivo and in vitro on PHB have clearly demonstrated its complete biodegradability and non-toxicity and hence its biocompatibility. ${ }^{2}$ The monomers formed after biodegradation of PHB are those that are found as intermediates in metabolic pathways of all higher organisms. 3-hydroxybutyric acid is the main biodegradation product of PHB, similar intermediates are found in humans.

The present article focuses the recent developments in various applications of PHB as biodegradable polymer in biomedical field.

\section{Brief history of PHB}

PHB was first discovered by Maurice Lemoigne in Pasteur Institute, Paris in 1925 during study on Bacillus megaterium. ${ }^{4}$ It is accumulated by variety of microorganisms during their growth on carbon rich and nitrogen limiting conditions. ${ }^{5}$ PHB has been seen as an eco-friendly substitute for synthetic thermoplastics as it posses properties similar to the synthetic polymer (polypropylene) and is completely biodegradable under natural conditions after its disposal. Therefore, replacement of non-biodegradable polymers by truly biodegradable and eco-friendly polymers like PHB will help to combat environmental problems created due to the production, use and disposal of synthetic polymers, ${ }^{6}$ use of biodegradable polymers in different field will have numerous advantages. Synthesis of PHB is the enzyme catalyzed reaction which converts acetyl-CoA to PHB. Research efforts have led towards the large scale production of PHB with lower production cost. When large amount of bio-plastics are available for exploitation then development in new applications are expected. Monsanto take 'BiopolTM' assets commercially available bio-plastic and further sold to Metabolix. Metabolix demonstrates high yield production of bio-plastic at laboratory scale.

\section{In tissue engineering scaffolds}

PHB has found good applications in tissue engineering scaffolds, the ideal material properties of PHB such as compatibility, support cell growth, guide and organize cells allow its applications in tissue growth. ${ }^{7,8}$

\section{In cell growth}

PHB has also found as a good biomaterial for growth of various cells including fibroblasts, ${ }^{9}$ osteoblasts, ${ }^{10}$ cartilage derived chondrocytes, ${ }^{11}$ human umbilical vein endothelial cells and rabbit aorta smooth muscle cells $^{12}$ as it is easily metabolized in the biosynthetic pathway of cell.

\section{In reconstructive surgery}

Slow and in vivo degradability of PHB proves it a potential and good candidate material for use in reconstructive surgery and in the development of cardiovascular products such as pericardial patches, vascular grafts, heart valve. ${ }^{13,14}$

\section{In controlled drug delivery system and surgery aids}

In controlled-release drug delivery systems a carrier material that is harmless to an organism and having necessary physical, mechanical and biomedical properties including degradability in biological media is needed. Since PHB and its derivatives fulfill these criterions they have good potential applications in controlled drug release system, ${ }^{15,16}$ surgical pins, sutures, swabs, wound dressing, bone replacements and plates, cartilage remodeling, and orthopedic uses. ${ }^{17-20}$

Wang \& Bakken ${ }^{21}$ have reported that PHB could be particularly used as biodegradable carriers for long term dosage of drugs, medicines and hormones. Turesin et al. ${ }^{22}$ reported that PHB also suitable as biodegradable drug carriers. 


\section{As peripheral etc. substitutes and implants}

PHB is used as a pericardial substitute, ${ }^{23}$ blood vessel replacements, stimulation of bone growth and healing by piezoelectric properties, cardiovascular, dental implants etc. The advantage of using biodegradable plastics during implantation is that it will be biodegraded eliminating the need of surgical removal.

Sodian et al. ${ }^{24}$ reported that PHB can be used to fabricate threedimensional, porous, biodegradable heart valve scaffold.

\section{In treatment of various diseases}

The degradation products of PHB i.e. 4-hydroxy butyrate (HB) units are pharmacologically active compounds and therefore are very suitable for treatment of various diseases such as alcohol withdrawal syndrome, narcolepsy, chronic schizophrenia, catatonic schizophrenia, atypical psychoses, chronic brain syndrome, neurosis, drug addiction and withdrawal, Parkinsons's disease, circulatory collapse, radiation exposure, cancer and other neuropharmacological illnesses. HB (4-hydroxy butyrate) units has been found useful in the treatment of narcolepsy, a chronic sleep disorder found in humans that generally starts at early adulthood and result in sudden sleep attacks, paralysis and sometimes temporary loss of muscle tone. HB act as a neurotransmitter in mammalian central nervous system as it is chemically closely related to gamma amino-butyric acid (GABA- a muscle tone regulator), it acts on the GABA receptor and reduces the narcolepsy. GABA that regulates the muscle tone. ${ }^{25,26}$

\section{Conclusion}

Among the various biodegradable polymers of microbial origin, PHB has been considered as an ideal candidate in medical field due to its various useful properties for various potential applications in biomedical and health field. Further research in the development and preparation of bio-plastic with additional properties desired for medical applications is expected to enhance the further biomedical application of PHB.

\section{Acknowledgements}

None.

\section{Conflict of interest}

The author declares no conflict of interest.

\section{References}

1. Wani SJ, Shaikh SS, Sayyed RZ. Microbial biopolymers: a initiative step towards green plastic. International Journal of Scientific \& Engineering Research. 2015;6(6):1339-1347.

2. Shishatskaya EI, Voinova ON, Goreva AV, et al. Biocompatibility of polyhydroxybutyrate microspheres: in vitro and in vivo evaluation. $J$ Mater Sci Mater Med. 2008;19(6):2493-2502.

3. Lee SY. Bacterial polyhydroxyalkonates. Biotechnol Bioeng. 1996;49(1):1-14.

4. Lemoigne M. Production of $\beta$-hydroxybutyric acid by certain bacteria of the B. subtilis group. Annales de Institut Pasteur Microbiology. 1925;39:144-56.

5. Sayyed RZ, Chincholkar SB. Production of Poly- $\beta$-hydroxy butyrate (PHB) from Alcaligenes faecalis. Indian $J$ of Microbiology. 2004;44(4):269-272.
6. Suresh Kumar M, Mudliar SN, Reddy KM, et al. Production of biodegradable plastic from activated sludge generated from the food processing industrial wastewater treatment plant. Bioresour Technol. 2004;95(3):327-330

7. Manavitehrani I, Fathi A, Badr H, et al. Biomedical Applications of Biodegradable Polyesters. Polymers. 2016;8:20-52.

8. Sokolsky PM, Agashi K, Olaye A, et al. Polymer carriers for drug delivery in tissue engineering. Adv Drug Deliv Rev. 2007;59(4-5):187-206.

9. Wang YW, Wu Q, Chen GQ. Reduced mouse fibroblast cell growth by increased hydrophilicity of microbial polyhydroxyalkanoates via hyaluronan coating. Biomaterials. 2003;24(25):4621-4629.

10. Wang YW, Wu Q, Chen GQ. Attachment, proliferation and differentiation of osteoblasts on random biopolyester poly(3hydroxybutyrate-co-3hydroxyhexanoate) scaffolds. Biomaterials. 2004;25(4):669-675.

11. Deng Y, Zhao K, Zhang XF, et al. Study on the three dimensional proliferation of rabbit articular cartilage derived chondrocytes on polyhydroxyalkanoate scaffolds. Biomaterials. 2002;23(20):4049-4056.

12. Qu XH, Wu Q, Zhang KY, et al. In vivo studies of poly(3-hydroxybutyrateco-3-hydroxyhexanoate) based polymers: biodegradation and tissue reactions. Biomaterials. 2006;27(19):3540-3548.

13. Kretlow JD, Klouda L, Mikos AG. Injectable matrices and scaffolds for drug delivery in tissue engineering. Adv Drug Deliv Rev. 2007;59(4 5):263-273.

14. Seyednejad H, Gawlitta D, Dhert WJA, et al. Preparation and characterization of a three-dimensional printed scaffold based on a functionalized polyester for bone tissue engineering applications. Acta Biomater. 2011;7(5):1999-2006.

15. Doi Y, Abe H. Control release of lastet, an anticancer drug from poly(3-hydroxybutyrate) microspheres containing acylglycerols. Macromolecular Reports. 1992;29(3):229.

16. Colin WP, Akhtar S. Biosynthesis polyhydroxyalkanoates and their potential in drug delivery. Advanced Drug Delivery Review. $1996 ; 18(2): 133-162$.

17. Sin LT, Rahmat AR, Rahman WAWA. 3-Applications of poly(lactic acid). In: Ebnesajjad S, editor. Handbook of Biopolymers and Biodegradable Plastics. USA: William Andrew Publishing; 2013. p. 55-69.

18. Diaz A, Katsarava R, Puiggali J. Synthesis, properties and applications of biodegradable polymers derived from diols and dicarboxylic acids: From polyesters to poly(ester amide)s. Int J Mol Sci. 2014;15(5):7064-7123.

19. Little CJ, Bawolin NK, Chen X. Mechanical properties of natural cartilage and tissue-engineered constructs. Tissue Eng Rev. 2011;17(4):213-227.

20. Hocking PJ, Marchessault RH. Biopolyesters in chemistry and technology of biodegradable Polymers. Griffin GJL, editor. London: Chapman and Hall; 1994. p. 48-96.

21. Wang JG, Bakken LR. Screening of soil bacteria for poly- $\beta$ hydroxybutyric acid production and its role in the survival of starvation. Microb Ecol. 1998;35(1):94-101.

22. Turesin F, Gursel I, Hasirci V. Biodegradable polyhydroxy alkanoate implants for osteomyclitis therapy: in vitro antibiotic release. J Biomater Sci Polym Ed. 2001;12(2):195-207.

23. Vacanti JP, Mayer JE, Langer R, et al. Tissue engineering heart valve leaftet replacement study in a lamb model. Ann Thorac Surg. 1995;60(6 Suppl):S513-S516.

24. Sodian R, Sperling JS, Martin DP, et al. Fabrication of a trileaflet heart value scaffold from a polyhydroxy alkanoate biopolyester for use in tissue engineering. Tissue Eng. 2000;6(2):183-188. 
25. Watanabe M, Maemura K, Kanbara K, et al. GABA and GABA receptors in the central nervous system and other organs. Int Rev Cytol. 2002;213:1-47.
26. Brandl H, Gross RA, Lenz RW, et al. Pseudomonas oleovorans as a source of poly(3-hydroxyalkanotes) for potential application as biodegradable polyesters. Appl Environ Microbiol. 1988;54(8):1977-1982. 